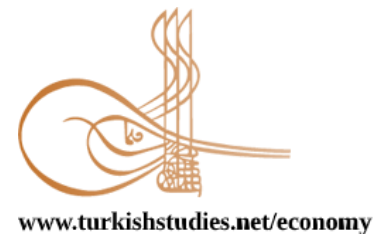

Turkish Studies - Economics, Finance, Politics

\title{
Rodrigo Duterte Dönemi Filipinler’in Güney Çin Denizi Sorunu Bağlamında Küresel Güçlerle İlişkileri
}

\author{
Philippines' Relations with Global Powers in the Context of the Southern China Sea Issue in \\ Rodrigo Duterte Period
}

\author{
Halit Hamzaoğlu*
}

\begin{abstract}
The article examines the main trends of the foreign policy of Rodrigo Duterte, who was elected President of the Philippines in 2016. The main problematic of the article is the content and method of balance policies that Duterte tries to build among the great powers. In this context, the balance policy between the US, traditional ally of the Philippines, and China, the rising power, during the Duterte period is analyzed. The difficulties faced by the Duterte administration within the scope of these balance policies were analyzed. The article emphasizes that the main subject of the balance policy that Duterte tries to implement is the national interests of the Philippines. Duterte's political attitude within the framework of the South China Sea problem has been associated with the discourse of economic cooperation used in its relations with China. Duterte has a foreign policy perspective that reads economic and military transformations in the current international system successfully. It maintains prudent and mutually beneficial relations with the US under the Trump, but also deepens economic and strategic cooperation with its giant neighbor China. On the other hand, it is emphasized that the security concerns of the Philippines are not fully adopted by the traditional ally of the USA and that this attitude of the USA leads Duterte to seek alternative relations in foreign policy. Therefore, it is possible to say that not only economic cooperation but also the security problem has come to the fore in relations with China. The Philippines leader follows a multi-dimensional foreign policy in the complicated geopolitical balance in the Asia-Pacific region. The Philippines also prioritizes its relations with Russia because of the security threat to its south. Cooperation with Russia in the military-technological field is gaining importance, especially in the context of combating extremist and separatist groups who resort to violence within the country.
\end{abstract}

Structured Abstract: The main motivation of the international relations of the Philippines during the Duterte period is the construction of a pragmatic and independent foreign policy strategy in the context of the Southern China Sea issue and the determination of balance policies and economic cooperation between the USA, China, and Russia as a priority area. The Southern China Sea issue has become one of the actual problems of international relations in the 21 st century. Thanks to its extensive economic development, China has significantly increased its naval capacity and embodied its determination in the context of claims on the

\footnotetext{
* Dr. Öğr. Üyesi, Kars Kafkas Üniversitesi, İktisadi ve İdari Bilimler Fakültesi, Siyaset Bilimi ve Uluslararası İlişkiler Bölümü

Asst. Prof. Dr. Kars Kafkas University, Faculty of Economics and Administrative Sciences, Department of Political Science and International Relations

ORCID 0000-0001-5249-1911

halithamzaoglu85@gmail.com
}

Cite as/ Atıf: Hamzaoğlu, H. (2020). Duterte Dönemi Filipinler dış politikasının temel eğilimleri. Turkish Studies -

Economy, 15(3), 1353-1365. https://dx.doi.org/10.47644/TurkishStudies.42266

Received/Geliş: 24 March/Mart 2020

Received/Geliș: 24 March/Mart 2020

Accepted/Kabul: 20 September/Eylül 2020

Accepted/Kabul: 20 September/Eylül 2020

Copyright (C) INTAC LTD, Turkey

Copyright (C) INTAC LTD, Turkey 
Southern China Sea. The examination of this motivation with its basic aspects constitutes the main problematic of the article.

The Southern China Sea issue is a regional issue with strategic and geopolitical dimensions as well as the legal parameter. Therefore, it is the geopolitical field in which China's regional hegemony attempts have turned into a concrete category. The great powers that have the opportunity to influence the geopolitical configuration of the region try to open a certain area for themselves within the framework of this problem. The solidarity and direction of behaviour between other regional actors and countries coming together around ASEAN shall determine the basic parameter, development and scale of the problem. China's hegemonic aspirations for the region play an important geopolitical function that involves the US and even Russia in the problem. It causes the Southern China Sea issue to gain an international framework. Geopolitical competition around the Southern China Sea issue pits China and the USA. The problem, which is a part of the global competition of China and the USA, has gained another dimension with Duterte's appointment. In this framework, Duterte's new approach based on economic cooperation with China has brought a multi-layered dimension to the South China Sea issue. The Duterte administration had a more cautious attitude towards relations with the United States, the traditional ally of the Philippines. This behaviour can be explained by the Philippines' desire to make maximum use of China's regional economic power and, most essentially, its large investments. It is a reflection of the pragmatic line of behaviour of the Duterte administration that the Philippines has established and developed a cooperation mechanism with countries that it does not have traditionally good relations with. Duterte exhibits a political attitude that diversifies the foreign policy behaviour of the Philippines and prioritizes mutually beneficial partnerships. Diversifying relations in line with the strategic goal that reduces the traditional alliance and dependency with the USA is the primary foreign policy vision. The Duterte administration, trying to develop a relationship with the Trump administration based on mutual understanding, produces political discourse in relations with China that excludes the possibility of geopolitical conflict caused by the Southern China Sea issue. The nature of relations with China develops through joint economic projects in line with new international relations dynamics. Approaching China's "One Belt - One Road" initiative from a positive perspective, Duterte tries to make maximum use of the opportunities of regional development. It is possible to observe that the Philippines, a key part of the Trump administration's Asia-Pacific strategy, try to exploit the regional geopolitical struggle that exists between the USA and China in their favour within the framework of balance policies. Duterte considers Russia as an alternative power centre in order to reduce the regional hegemonic desires of the USA and China, which can directly affect the internal dynamics and foreign policy configuration of the country. The main priority in relations with Russia is developing towards arms imports. Russia also cares about Duterte's tactical discourses on the world order from the perspective of multipolar international relations.

In modern international relations, many countries determine their balance policies as their main strategic priority. In this context, the Philippines, which is an important actor in the Asia-Pacific region, is no exception. Elected President of the Philippines in 2016, Rodrigo Duterte tries to implement the said balance policies. The Philippines leader follows a multi-dimensional balance strategy between its traditional ally, the USA and China, in the harsh conditions of the current international system. Duterte acts on the assumption that China's economic power offers a constructive perspective in favour of his country. On the other hand, he does not completely turn away from his traditional ally, the USA. In particular, he takes steps towards building a political cooperation with Trump based on mutual interests.

The tactical dimension of the relations developed by the Philippines with China in recent years has the potential to gain a strategic framework in the mid-term. The strategic framework in question poses a challenge for the USA's Asia-Pacific policies. For this reason, the Trump administration desires not to lose its historical superiority and gains over the Philippines. US military bases in the Philippines are of great importance from the perspective of Trump's strategy to contain China. For the Trump administration, the Philippines' leaving the sphere of influence, which is the key country in the geopolitical line of the region, is a major strategic loss. On the other hand, Duterte wants to benefit the most of the geopolitical competition between the USA and China. In the context of balancing the two great powers in military terms, building good relations with Russia is among the priorities of its foreign policy. Military cooperation with Russia comes to the fore within the scope of fighting extremist groups in the south of the Philippines.

Duterte has determined reducing the severity of the unilateral hegemony established by the USA on the Philippines and diversifying its relations with China as its main strategic priority. In this respect, he did

Turkish Studies - Economy, 15(3) 
not hesitate to take a step back in the South China Sea issue with China and prioritized building a whole of relations based on economic cooperation. It cannot be said that Duterte has a political line that adopts anti-US policies. It is possible to say that the Philippine leader acts with the perspective of national interest in the multipolar system and follows the strategy of balance policy.

Keywords: China, Duterte, International Relations, Philippines, USA

Öz: Makale, 2016 yılında Filipinler Cumhurbaşkanı seçilen Rodrigo Duterte'nin dış politikasının temel eğilimlerini incelemektedir. Duterte'nin büyük güçler arasında inşa etmeye çalıştığı denge politikalarının içeriği ve yöntemi makalenin temel sorunsalını oluşturmaktadır. Bu çerçevede Filipinler'in Duterte döneminde geleneksel müttefiki $\mathrm{ABD}$ ile yükselen bir güç olan Çin arasında nasıl bir denge politikası izlediği analiz edilmektedir. Duterte yönetiminin söz konusu denge politikaları kapsamında karşı karşıya geldiği zorluklardan bahsedilmiştir. Duterte'nin uygulamaya çalıştı̆ı denge politikasının merkezi konusunun Filipinler'in ulusal çıkarlarını sağlanması olduğu makalede özellikle vurgulanan hususlardandır. Duterte'nin Güney Çin Denizi sorunu çerçevesindeki politik tutumu ile Çin ile ilişkilerini ekonomik işbirliği söylemi temelinde oluşturma stratejisi ilişkilendirilmiştir. Duterte güncel uluslararası sistemdeki ekonomik ve askeri dönüşümleri iyi okuyan bir dış politika perspektifine sahiptir. Trump yönetimdeki ABD ile ihtiyatlı ve karşlıklı çıkarlara dayalı ilişkileri devam ettirmekte, fakat bunun yanında dev komşusu Çin ile ekonomik ve stratejik işbirliğini giderek derinleştirmektedir. Diğer taraftan ise Filipinler'in güvenlik kaygılarının geleneksel müttefiki ABD tarafından tam anlamıyla benimsenmediği ve ABD'nin bu tutumunun Duterte'yi dış politikada alternatif ilişkiler inşa etme arayışına yönelttiğinin üzerinde durulmuştur. Dolayısıyla, Çin ile ilişkilerde sadece ekonomik işbirliğinin değil, aynı biçimde güvenlik sorunsalının da ön plana çıktığını söylemek mümkündür. Filipin lideri Asya - Pasifik bölgesinde var olan çetrefilli jeopolitik denklemde çok boyutlu bir diş politika izlemektedir. Filipinler'in güneyinde oluşan güvenlik tehdidi çerçevesinde Rusya ile ilişkileri de öncelemektedir. Özellikle ülke içerisinde şiddete başvuran aşırılıkçı ve ayrılıkçı gruplarla mücadele kapsamında Rusya ile askeri-teknolojik alandaki işbirliği önem kazanmaktadır.

Anahtar Kelimeler: Uluslararası İlişkiler, ABD, Çin, Duterte, Filipinler

\section{Giriş}

Rodrigo Duterte 9 Mayıs 2016 tarihinde gerçekleşen Cumhurbaşkanlığı seçiminde oyların \%39'nu alarak Filipinler Cumhurbaşkanı görevini kazanmıştır. Duterte'nin rakibi Filipinler yerleşik düzeninin önemli temsilcisi olan Liberal Parti adayı Mar Roxas ise oyların \%24'nü almıştır. Duterte Filipinler'in yerleşik siyasal düzenini temsil etmemekteydi ve bu açıdan seçim zaferi 'sansasyonel' olarak nitelendirilmekteydi. (Svedentsov, 2018:60) Filipinli seçmenlerin büyük çoğunluğunun geleneksel siyasal elitlerden herhangi bir beklentileri yoktu ve bu çerçevede yerleşik politik figürlerden adeta yılmış durumdaydılar. Seçmenler altı yıl boyunca ülkeyi yönetmek için yeni bir yüze, güçlü ve karizmatik bir kişiliğe sahip lider arayışındaydılar. (Sevilla,2018:166) Duterte seçmenlerin arayışlarına uygun bir politik kişilikti. Bu sebeple Filipinlilerin talep ve arzularını güçlü bir biçimde konsolide etmiş ve ülkesi açısından tarihi bir seçim zaferi kazanmaya muvaffak olmuştu.

Duterte'nin siyasi kariyeri 1988'de Mindanao bölgesinde bulunan Davao kentinin Belediye Başkanı seçilmesiyle başlamıştır. 1998 yılına kadar bu görevi sürdüren Duterte, daha sonra Davao'dan Filipinler Temsilciler Meclisine seçilmiştir. 2001'de ise yeniden Davao Belediye Başkanlığı görevine seçilmiştir. Görevi süresince Davao istikrarlı bir büyüme sergilemiş ve dünyada hızla büyüyen şehirler listesine dâhil olmuştur. (Svedentsov, 2018:61) Duterte Filipinler tarihinde yerel yöneticilikten gelen ve bu bağlamda Cumhurbaşkanlığg görevine doğrudan seçilen ilk siyasi figürdü. (Gavilan, 2016) Aynı zamanda güneydeki Mindanao bölgesinden seçilen ilk Cumhurbaşkanıydı.(Gavilan,2016) Duterte, Davao kentinde elde ettiği istikrarlı gelişsim modeli deneyimini Cumhurbaşkanı seçildikten sonra bütün ülkede uygulamaya koymuştur. (Svedentsov, 2018:62) 
Duterte'nin Cumhurbaşkanı seçilmesi Filipinler'in geleneksel diş politika çizgisinde önemli değişiklikleri beraberinde getirmiştir. Amerika Birleşik Devletleri (ABD) yönlü geleneksel dış politika stratejisinin yerini Çin ve Rusya gibi güç merkezleriyle daha yakın işbirliği mekanizmaları almıştır. (Sevilla,2018:171) Filipinler tarihsel olarak ABD’nin en önemli Kuzey Atlantik Antlaşması Örgütü (NATO) üyesi olmayan müttefiki konumundadır. ABD muhtelif tarihlerde Filipinler'le yaptığı antlaşmalar-Karşılıklı Savunma Antlaşması (1951), Ziyaret Kuvvetleri Antlaşması (1999) ve on yıllık Geliştirilmiş Savunma İşbirliği Antlaşmaları (2014) çerçevesinde bu ülkede askeri açıdan mevcudiyet göstermektedir. (Steinbock, 2016) Duterte ilişkilerini çeşitlendirmek ve ABD’ye olan bağımlığı azaltma amacıyla bağımsız dış politika ilkesi perspektifiyle hareket etmeyi önceleyen bir siyasi tasavvura sahiptir. Bu bağlamda Duterte'nin Filipinler - Çin ile ilişkilerine yön veren temel konu olan Güney Çin Denizi sorunu bağlamındaki tutumu oldukça önemliydi. Duterte pragmatik hedefleri gözeterek Çin ile ekonomik işbirliğini geliştirme yolunu tercih etmiştir. Duterte, Güney Çin Denizi sorunu çerçevesinde Çin ile yapıcı görüşmelere istekli davranmış, iki ülkenin yoğun ekonomik işbirliğini desteklemiş ve FilipinlerABD geleneksel ittifakına eleştiriler getirmiştir. (Steinbock, 2016)

Duterte dönemi Filipinler'in uluslararası ilişkilerinin temel motivasyonunu Güney Çin Denizi sorunu bağlamında pragmatik ve bağımsız dış politika stratejisinin inşa edilmesi ve aynı zamanda $\mathrm{ABD}$, Çin ve Rusya arasında denge politikalarının ve ekonomik işbirliğinin öncelikli alan olarak belirlenmesi teşkil etmektedir. Söz konusu motivasyonun temel yönleriyle incelenmesi makalenin esas sorunsalını oluşturmaktadır. Makalenin ilk bölümünde Güney Çin Denizi sorununun tarihsel arka planından ve Duterte'nin soruna bakışı ele alınmıştır. İkinci bölümde ise Duterte'nin ABD, Çin ve Rusya arasında inşa etmeye çalıştığı denge politikalarından bahsedilmiştir. Sonuç bölümünde ise Duterte'nin izlediği dış politika davranışlarının genel bir değerlendirmesi yapılmıştır.

\section{Güney Çin Denizi Sorunu ve Duterte'nin Tutumu}

Güney Çin Denizi stratejik, jeopolitik ve ulaşım açısından oldukça önemli coğrafi bir alandır. Hint Okyanusundan Pasifiğe açılan temel rota bu alandan geçmektedir. Uluslararası ticaretin ana güzergâhı olan Güney Çin Denizi, Orta Doğu ile Doğu Asya ve Güney Pasifik'i birbirine bağlayan transit ulaşımın kesişme noktasındadır. Pratas Adaları, Paracel Adaları, Scarborough kayalıkları ve Spratly Adaları jeopolitik sorunların yaşandığı adalardır. Güney Çin Denizi'nde "hak iddia eden devletler ise Çin, Tayvan, Vietnam, Filipinler, Malezya ve Brunei'dir." (Pekcan, 2017:56) Stratejik öneminin yanında Güney Çin Denizi zengin hidrokarbon yataklara sahiptir. Paracel adalarında ve Spratly takımadalarında yaklaşık 5,4 milyar varil keşfedilen petrol rezervi ve aynı zamanda 55,1 trilyon metreküp doğal gaz rezervi bulunmaktadır.(Novoseltsev, 2018:89)

Çin adaların tamamı üzerinde hak iddia ederken, Vietnam Paraceller ve Spratly'e, Filipinler Spratly ve Scarborough'a, Malezya ve Brunei ise Spratly adalarının birkaçı üzerinde hak iddia etmektedir. (Bader vd, 2014:4) Çin 1974'de Paraceller üzerinde kontrol sağlamıştır. Spratly adalarının büyük çoğunluğunda ise Vietnam egemenliği söz konusudur. Çin ve Filipinler ise Spratly adalarının yedi veya sekizinde kontrolü ele almıştır.(Bader vd, 2014:4) Çin bölgedeki nüfuzunu artırmaya devam ettirmiş ve adaları askeri deniz üsleri olarak kullanmaya başlamıştır. Böylelikle, diğer kıyıdaş ülkeler açısından güvenlik temelli sorunlar meydana çıkmıştır. (Choi, 2017:3)

Güney Çin Denizi sorunu onlarca yıldır gelişmekte olan, bölgesel güvenlik açısından risk arz eden ve henüz barışçıl bir çözüme kavuş̧urulmayan bir sorundur. (Rustandi, 2016:2) Ekonomik ve jeopolitik çekiciliğine karşın, bölgenin açık bir şekilde belirlenmiş düzenleyici statüsünün olmaması krizlere ve politik olaylara zemin hazırlamaktadır. (Novoseltsev, 2018:89) 
Güney Çin Denizi meselesi 21. Yüzyılda uluslararası ilişkilerin güncel sorunlarından biri haline gelmiştir. Çin çok kapsamlı ekonomik gelişimi sayesinde deniz gücü kapasitesini önemli bir ölçüde artırmış ve Güney Çin Denizine yönelik hak iddiaları bağlamında kararlılığını somutlaştırmıştır. ABD ise yükselen bir güç olan Çin'e karşı bölgedeki stratejik varlığını güçlendirmek amacıyla Asya-Pasifiğe yönelmiştir. (Forsby, 2016:12) Bölgesel anlaşmazlıklar sorunun uluslararasılaşmasına ve çatışma riskinin artmasına neden olmaktadır. Bu bağlamda uzun yıllar boyunca kendini tarafsız olarak konumlandıran ABD bölgedeki askeri mevcudiyetini artırma eğilimine girmiştir.

Bölgedeki en kapsamlı hak iddiası Çin'e aittir. 'Dokuz nokta çizgisi' ilkesine ve bu bağlamda 'tarihi' haklarına vurgu yapmaktadır. Çin 1947 yılındaki 'tarihi atlasa' dayanarak haklarının \%80'den fazla olduğu görüşünü savunmaktadır. Filipinler, Malezya ve Brunei ise 1982 yılındaki Birleşmiş Milletler (BM) Deniz Hukuku Sözleşmesi hükümlerine vurgu yapmaktadırlar. (Kapustin, 2017:208)

Çin ve Filipinler arasındaki sorunlar özellikle Scarborough adaları ve Reed Bank coğrafi bölgesinde tezahür etmektedir. .Üçgen şekilli bir lagün olan Scarborough suyun üzerinde yükselen küçük adalardan oluşmaktadır. Reed Bank bölgesi ise BM Deniz Hukuku Sözleşmesine göre Filipinlerin münhasır ekonomik bölgesine dâhildir. Bu çerçevede Filipinler münhasır bölge içerisindeki kaynakları geliştirme ve kullanma hakkına sahiptir.(Kozlov, 2018: 4) Filipinler "hak iddialarını adaların 1956'da Filipinli bir kâşif tarafindan keşfedilmesine ve yarı-yasal bir kavram olan 'yakınlık' kavramına dayandırmaktadır.” (Pekcan, 2017:61)

Çin'in tarihsel hak iddiaları ile karşılaştırıldığında, Filipinler'in adalara yönelik iddiaları yakın bir dönemi kapsamaktadır. 1972 yılında Filipinler ilk kez Güney Çin Denizinde yer alan 53 adalar grubuna dair resmi düzeyde talepte bulunmuştur. Filipinler, Çin'in uluslararası toplum tarafından geniş kabul gören BM Deniz Hukuku Sözleşmesi kapsamında izin verilen hakların çok üzerinde iddiaları olduğunu vurgulamaktaydı. (Wiegand vd, 2018:4) 1995 yılında "Çin'in üzerinde hak iddia ettiği Mischief resifini işgal etmesi ve resifteki askeri varlığını arttırması, iki ülkenin Güney Çin Denizi'nde gerginliğinin ortaya çıkmasına neden olmuştur.” (Keyvan, 2017:254)

Bölgedeki en önemli organizasyon olan ASEAN (Güney Doğu Asya Uluslar Birliği) Güney Çin Denizi bağlamındaki sınır ve egemenlik sorunlarını çözme istikametindeki çok taraflı görüşmeleri desteklemiş ve 2002 yılında Çin ile 'Tarafların Davranışları Hakkında bir Bildirge' imzalanmıştır. Söz konusu bildirge tehdit söylemi ve güç kullanımı olmadan, sorunun uluslararası hukuk çerçevesinde barışçıl çözümüne vurgu yapmaktadır. (EU-Asia Centre, 2013:1) Ancak ASEAN ülkelerinin her birinin kendi ulusal çıkarları doğrultusunda hareket etmesi süreci işlevsiz hale getirmekteydi. 2011-2016 yılları arasında Güney Çin Denizindeki bölgesel egemenlik iddiaları çok taraflı çatışma riskini de beraberinde getirmekteydi.

Nisan 2012'de taraflar arasındaki tarihsel gerilim tırmanmış ve sıcak bir çatışmaya dönüşmüştür. Bu kapsamda Çin, Filipinler'in kontrolünde olan Scarborough'daki bazı bölgeleri ele geçirmiştir. 2013'de Filipinler Çin'le yaşadığ 1 anlaşmazlık nedeniyle Lahey uluslararası tahkim mahkemesine başvurmuştur. (Wiegand vd, 2018:4) Uluslararası tahkime sunulan Filipin tezlerinin temel gerekçesi Çin'in iddialarının BM Deniz Hukuku Sözleşmesi çerçevesinde tutarsız, çelişkili ve geçersiz olması üzerine şekillenmiştir. (Wiegand vd, 2018:4) 2016 yılında tahkim mahkemesi Filipin tezlerini onaylayan bir karar vermiştir. Mahkeme kararında, "Çin'in Güney Çin Denizi'nin nerdeyse tamamını işgal etmesinin yasal bir dayanağının bulunmadığını belirtmiştir." (Keyvan, 2017: 257) Tahkim mahkemesinin kararı "uluslararası düzeyde anlaşmazlıkların çözümü açısından tahkim mahkemesini çekici bir hale getirmiş ve benzer sorunlar bağlamında bir çözüm yöntemi" sunmuştur. (Wiegand vd, 2018:11) Duterte'den önceki Aquino yönetimi perspektifinden tahkim kararı 'tam bir zafer' niteliği taşımaktaydı. (Kreuzer, 2018:14) 
Fakat genel anlamda Güney Çin Denizi sorunu hukuki parametrenin yanında stratejik ve jeopolitik boyutlar taşıyan bir bölgesel meseledir. Dolayısıyla, Çin'in bölgesel hegemonya girişimlerinin somut bir kategoriye dönüştüğü jeopolitik alandır. Bölgenin jeopolitik konfigürasyonuna etki etme imkânına sahip büyük güçler bu sorun çerçevesinde kendilerine belirli bir alan açma çabası taşımaktadırlar. Diğer bölgesel aktörler ve ASEAN etrafında bir araya gelen ülkeler arasındaki dayanışma ve istikametteki davranış şekli sorunun temel parametresini, gelişimini ve ölçüsünü belirleyecektir. Çin'in bölgeye yönelik hegemonik istekleri ABD ve hatta Rusya'yı soruna dâhil eden önemli bir jeopolitik işlev rolünü oynamaktadır. Bu da Güney Çin Denizi sorunun uluslararası bir çerçeve kazanmasına neden olmaktadır.

Güney Çin Denizi sorunu etrafında şekillenen jeopolitik rekabet Çin ve ABD'yi karşı karşıya getirmektedir. Çin ve ABD'nin küresel rekabetinin bir parçası olan söz konusu sorun Duterte'nin görev başına gelmesiyle bir başka boyut kazanmıştır. 2010-2016 yıllarında iş başında olan Aquino yönetimi sorunun uluslararasılaştırmak eğilimindeydi ve bu çerçevede ABD, Avusturalya ve Japonya ile daha yakın güvenlik ilişkileri kurarak dış dengeyi güçlendirme stratejisi izlemekteydi. (Kreuzer, 2018:1) Duterte ise daha önce Gloria Macapagal Arroyo (2001-2010) yönetiminin benimsediği stratejiyi genişleterek ekonomik işbirliği yöntemiyle çatışma ve gerginliği azaltma yolunu tercih etmekteydi. (Kreuzer, 2018: 2)

Duterte "Filipinlerin tahkim mahkemesinin kararını görmezden geleceği taahhüdünde bulunarak" Çin'in hukuksal yenilgisini kabul etmek zorunda kalmadan politika değişimine gitmesine ve çatışmanın dinamiğini azaltmasına olanak sağladı. (Kreuzer, 2018:2) Böylelikle, Duterte Güney Çin Denizindeki anlaşmazlıklarla başa çıkmanın bir yolu olarak Çin ile ilişkilerde uzlaşmacı bir tavır sergileme tutumu benimsedi. Söz konusu tutum Çin'i Filipinlerin ABD ile var olan geleneksel ittifaka karşı bir dengeleyici aktör olarak görmeyi mümkün kılmaktaydı. (Shoji, 2017:133) Güney Çin Denizi politikalarında ve bu açıdan ortaya çıkan çatışma noktalarında Çin ile uzlaşmacı ve istişare odaklı bir perspektif geliştirmesi Duterte yönetiminin soruna bakışının karakteristik özelliğini oluşturmaktaydı. (Shoji, 2017:134) Duterte'nin Çin ile geliştirmeye çalıştı̆̆ ekonomik işbirliği temelli yeni yaklaşımı Güney Çin Denizi sorununa çok katmanlı bir boyut kazandırmıştır.

\section{Duterte'nin Denge Politikaları}

\section{1. Çin ve ABD ile İlişkiler}

Duterte yönetimi Filipinlerin geleneksel müttefiki ABD’nin etkisinden kurtulmak için Çin'in bölgesel rolünü yeniden biçimlendiren ve bu bağlamda ekonomik kalkınma odaklı perspektif ihtiva eden politikaları öncelemeye başlamıştır. (Svedentsov, 2018:60) Duterte 2016'da göreve başlarken daha bağımsız bir dış politika yürüteceğini ve Çin ile ilişkileri iyileştireceğini vurgulamaktaydı. (Cook, 2019:1) Duterte ABD politikalarına karşı Çin'i dengeleyici olarak gören ilk Filipinli lider değildir. 2001-2010 yılları arasında yönetimde bulunan Gloria Macapagal Arroyo ABD eğilimli geleneksel politik paradigmadan kurtulmaya çalışmıştır. Bu bakımdan Duterte yönetiminde de Dış Politika Başdanışmanı görevini üstlenen Arroyo Filipinler'in Çin ile daha yakın etkileşimini başlatan siyasal bir figürdür. (Svedentsov, 2018:66) Duterte Arroyo'nun dış politika paradigmasını daha güçlü bir şekilde devam ettiren siyasal perspektif izlemektedir. ABD'nin bölgedeki tarihsel varlığına karşı çıkmakta, karşılığında ise Çin'i yeni ve güvenilir bir ortak olarak görmektedir. ABD'den bağımsız bölgesel politikalar geliştirmeye çalışan Duterte yönetimi Çin'i temel dengeleyici aktör olarak değerlendirmektedir. (Cook, 2019:2) Duterte Güney Çin Denizi sorunu çerçevesinde ABD'nin Filipinler'le gerçekleştirdiği taahhütlere bağlı kalacağına kuşkuyla bakmaktaydı. Bu açıdan Güney Çin Denizi sorununa reel politik perspektiften bakmakta ve kendine hareket alanı oluşturmaktaydı. Duterte'nin en önemli stratejik kaygılarından biri ve Çin ile ilişkileri normalleştirmesinin motivasyon kaynağı Barack Obama yönetiminin Güney Çin sorunu bağlamında Çin saldırganlığına karşı belirsiz tutumuydu. 
Seçim kampanyası sürecinde Duterte Filipinler ve Çin arasında yaşanacak olası bir çatışmada ABD'nin yardıma geleceğine inanmadığına dair önemli ipuçlarına yer vermişti. (Heydarian, 2018:2) Duterte'yi Çin ile ilişkileri normalleştirmeye iten önemli neden ABD yönetiminin güven teşkil etmeyen politik duruşuydu. $\mathrm{Bu}$ bağlamda uluslararası tahkim mahkemesinin Filipinler lehine verdiği kararı değerlendirmekte acele etmemeyi tercih etmiştir. Tam tersine güçlü komşusu Çin ile ortak zemin bulma arayışına girmiştir. Çin'in ekonomik büyüklüğ̈̈nden ve askeri gücünün avantajlarından faydalanmayı öncelemiştir. (Arugay,2018:4)

Duterte 30 Haziran 2016 tarihinde daha resmi göreve başlamadan önce ABD-Filipinler ittifakını küçümseyici tarzda hareket etmekte ve Çin ile ilişkilerde yakın işbirliğini savunmaktaydı. Aynı zamanda ülkesinin askeri modernizasyonunu devam ettireceğini vurgulamaktaydı. (Castro, 2016:146) Duterte'nin yeni dış politika stratejisi ABD, Japonya ve ASEAN ülkeleri sıralarında rahatsızlıklar meydana getirmekteydi. (Castro,2016:153) ABD perspektifinden Duterte'nin 27 Mayıs 1999'da yürürlüğe giren ve Amerikan askeri personelinin Filipin topraklarında bulunmasını sağlayan Ziyaret Kuvvetleri Antlaşması'nın (Visiting Forces Agreement) sorgulaması en arzu edilmeyen siyasal tavır olmuştur. Duterte Cumhurbaşkanlığ 1 görevinin ilk günlerinden itibaren ABD açısından stratejik önem arz eden söz konusu antlaşmadan ve hatta geniş anlamda FilipinlerABD ilişkilerinden vazgeçme noktasındaydı. (Kurlantzick,2020) Antlaşmanın sona erdirilmesi ABD'nin Asya-Pasifik bölgesindeki stratejik konumuna zarar verecek ve karşıllğında Çin çıkarlarına büyük katkı sağlayacaktır. (Kurlantzick,2020)

Duterte'nin 2016 yılında başlayan siyasi liderliği Asya-Pasifik coğrafyasındaki jeopolitik manzaranın dramatik bir biçimde değişimiyle örtüşmekteydi. 2016 yılında ABD ve Çin arasındaki bölgesel güç rekabet derinleşmiş, Japonya'nın stratejik hedeflerinin boyutu genişlemiş ve Kore yarımadasındaki istikrarsız durum su yüzüne çıkmıştır.(Vicedo, 2017:1) Bu bölgesel jeopolitik denklem güvenlik kaygılarının artmasına neden olmaktaydı. Duterte yönetimi söz konusu bölgesel gelişmeler 1şı̆̆ında dış politikada pragmatik bir yaklaşım geliştirmeyi tercih etmiştir. 2016'da ABD'de Başkanlık görevine gelen Trump'ın politik algılarının da bu yaklaşımda etkisi olmuştur. (Vicedo, 2017:1) Trump'ın Obama yönetiminden farklı olarak demokrasi ve insan hakları kavramlarına pragmatik bakışı Duterte'nin pozisyonunu güçlendiren etkenlerdendi. Diğer taraftan, Trump yönetiminin Çin'e karşı benimseyeceği daha sert politikalar (güç yoluyla barış politikası) Filipinler ve diğer bölge ülkelerine yönelik ABD baskısının azalacağı anlamına gelmekteydi. (Heydarian, 2018:2) Benzer siyasi retoriklere ve tarzlara sahip olan Duterte ve Trump'in nispeten sorunsuz bir ilişki geliştireceği öngörülmekteydi. 2017 yılının Kasım ayında Filipinler'in başkenti Manila'da gerçekleştirilen Duterte-Trump görüşmesi olumlu bir atmosfer ihtiva etmekteydi. (Kurlantzick, 2020) Trump görüşmede Filipinler- ABD ilişkilerini 'harika' olduğunu ifade etmekteydi. Trump “ABD’nin önceki yönetimlerinden farklı olarak, her zaman Duterte yönetiminin dostu olduğunun" altını çizmekteydi.(Davis, 2017) Fakat Duterte yönetimi geleneksel müttefiki ile ilişkilere daha temkinli bir davranış biçimine sahipti. Bu davranış biçimi Filipinler'in Çin'in bölgesel ekonomik gücünden ve en esası büyük yatırımlarından maksimum faydalanmak isteğiyle açıklanabilir.

Duterte Filipinlerin dış ve iç politika anlamında ABD'ye güvenerek bir strateji geliştirmeyeceğini, ülkesi açısından sömürge dönemlerinin geride kaldığını ve başka bir ülkenin yardımı olmadan da ayakta kalabilme potansiyellerinin olduğuna inanmaktaydı. (Panarina, 2016:93) Bu çerçevede 2014'de Filipinlerle ABD arasında imzalanan ve Amerikan askeri üslerinin ülke topraklarındaki sayısını artırmayı öngören askeri işbirliği antlaşmasını feshetmeye hazır olduğunu beyan etmekteydi. (Panarina, 2016:93) Duterte'nin hem seçim kampanyası döneminde hem de göreve gelmesinden sonra ABD karşıtı retoriğinde askeri üsler konusu önemli bir yer kapsamaktaydı. Fakat ABD askerlerini Filipin topraklarından geri çekme konusunda resmi talepte bulunmamıştır.(Panarina, 2016:97) Buradan çıkarılan temel sonuç Duterte'nin ABD karşıtı siyasi retoriğinin amacı Çin ile geliştirmek istediği denge politikalarına alan açma isteğiyle açıklanabilir. Dolayısıyla, geleneksel müttefik pozisyonunda olan ABD ile askeri ve ekonomik bağların ortadan 
kalkması söz konusu retoriğe rağmen mümkün gözükmemektedir. Bu bakımdan Duterte açısından iki büyük güç arasındaki jeo-stratejik sorunlara angaje olmadan dengeli bir bölgesel dış politika zeminin oluşması oldukça önemliydi.

Filipinler - Çin ilişkilerinin gelişimi açısından Duterte'nin Pekin ziyareti bir dönüm noktası teşkil etmiştir. Filipinler lideri ülkesi açısından tek mantıklı seçeneğin Çin ile karșılıklı ekonomik bağımlılığın artırılmasında görmekteydi. İki ülke arasındaki ekonomik bağımlılığın Güney Çin Denizindeki olası çatışmayı önleyeceği düşüncesi ağırlık kazanmaktaydı.(Castro, 2019:3) Duterte Cumhurbaşkanlığı görevine başladığında Çin öncüllüğünde geliştirilen stratejik 'Tek Yol Tek Kuşak' projesinin ekonomik getirilerinden faydalanmak niyetindeydi. (Castro, 2019:3) Duterte yönetimi tahkim mahkemesinde kazanılan yasal zafere rağmen, bu süreci Çin'i tahrik etmeyen bir olgunlukla ve aynı zamanda ihtiyatlı bir biçimde yönetmekteydi. (Castro, 2019: 4) Duterte'nin Çin ile ilişkilerindeki yumuşak tutumu Filipinler içerisinde eleştiriyle karşılanmaktaydı. Özellikle Güney Çin Denizi sorunu bağlamında Çin'e karşı izlenen 1lımlı politika Duterte'nin iç politikadaki siyasi rakiplerinin temel itiraz noktasıydı. (Fook, 2019:1)

Duterte'nin 20 Ekim 2016'da Çin'e gerçekleştirdiği resmi ziyarette ABD'den 'uzaklaşacağını' ve Çin ile 'uzun süreli ilişkiler' geliştireceğini açık bir biçimde ifade ederek siyasi gözlemcileri şaşırtmıştır. (Ibarra, 2017:1) Duterte Pekin ile Güney Çin Denizi sorunu kapsamındaki meselelerin müzakere yoluyla çözülmesini deklare etmiştir. (Blanchard, 2016:1) Çin Devlet Başkanı Şi Cinping Duterte'ye iki ülke arasında var olan sorunların pratik çözümünün ehemmiyetinden bahsetmekteydi. Şi ayrıca iki ülkenin kalkınma stratejilerini tam olarak koordine etmelerini ve işbirliği oluşturulması önermekteydi.(Castro,2019:4) Çin bir taraftan Güney Çin Denizindeki askeri potansiyelini artırırken, diğer taraftan rakiplerine ekonomik kalkınmaya yönelik yatırımlar ve krediler sağlamayı öncelemekteydi.

Ziyaret sırasında Duterte ve Çin Devlet Başkanı Şi Cinping uyuşturucu kaçakçılığı ve yasadışı balıkçılığa karşı mücadeleyi de kapsayan bir dizi antlaşma imzalamışlardır. Çeşitli ekonomik konularla ilgili 13,5 milyar dolarlık 13 antlaşma ikili ilişkileri güçlendirmeye yönelik ilk somut adım özelliği taşımaktaydı. Söz konusu antlaşmalar Filipin ekonomisine milyarlarca dolarlık Çin yatırımlarının önünü açmıştır. (Manukov, 2016:1) Duterte Çinli işadamlarıyla görüşmesi sırasında Filipinlerin "askeri ve ekonomik alanlarda ABD'den ayrıldığını" vurgulamış ve Amerikalı yöneticileri "kaba insanlar" olarak tanımlamıştır.(Manukov, 2016:1) Bu bağlamda Duterte'nin dış politika amacının Filipinler üzerindeki ABD etkisini sınırlandırma çerçevesinde şekillendiğini söylemek mümkündür. Diğer taraftan ise Çin ile yakınlaşma stratejisini önceleyen bir dış politika hedefi ortaya çıkmıştır. (Castro,2016:141) Böylelikle, Duterte'nin dış politika formasyonu Asya-Pasifik bölgesinde stratejik ve jeopolitik çıkarları olan iki büyük güç arasında denge oluşturmayı ve bu istikamette Filipinlerin hareket kabiliyetini artırmayı önceleyen bir çerçeveye sahipti. Duterte'nin dış politikasının temeli esasında geleneksel müttefiki ABD ile Çin arasında pragmatik bir dengeye dayanmaktaydı.

Duterte 2016-2019 yılları arasında Çin'i beş kez ziyaret etmiştir. 2017 yılının Mayıs ayında gerçekleştirilen ikinci ziyarette 2013'te Şi Cinping tarafından deklare edilen Tek Kuşak Tek Yol projesinin açılış forumuna katılmıştır. Söz konusu forumda Duterte ve yönetimi 'İnşa, İnşa, İnşa' (Build, Build, Build-BBB) programının tanıtımını yapmıştır.(Fook,2019:3) BBB programı Duterte yönetiminin Filipinler'deki 'altyapının altın çağını' başlatmayı amaçlayan stratejik bir hedefe sahipti. Altyapı eksikliği uzun yıllar Filipin ekonomik kalkınmasının 'aşil topuğu' olarak görülmekteydi. (National Government Portal, 2019:1) Çin hükümeti Tek Kuşak Tek Yol projesiyle BBB programının uyumluluğuna ve tamamlayıcı karakterine vurgu yapmıştır.(Fook, 2019:3)

Nisan 2018'deki ziyarette Filipinler'in suç, yasadış1 göç, terör ve şiddet içeren aşırıcılıkla mücadelede konularında Çin ile koordinasyonun önemine dikkat çekilmiştir. Aynı zamanda daha önceki ziyaretlerde temel konu olan ekonomik işbirliği sorunsalı müzakerelerin merkezinde yer almıştır. (Fook, 2019:3) Duterte 2018 ziyaretinden bir yıl sonra Şi Cinping'in davetlisi olarak 
ikincisi düzenlenen Tek Kuşak Tek Yol forumuna katılmıştır. Duterte'nin güçlü komşusuna gerçekleştirdiği dördüncü ziyaret kapsamında "Filipinler ve Çin arasında 12, 165 milyar dolar değerindeki en az 19 ticari ve yatırım anlaşması" imzalanmıştır. (Belt and Road News, 2019) Duterte yönetimi Filipinlerin üretim tabanının genişletilmesi ve ihracatı artırma amacıyla Çinli şirketlerin enerji sektörüne yönelik yatırımlarını özellikle önemsemekteydi. Bu çerçevede Duterte'nin Nisan 2019 tarihinde gerçekleştirdiği Çin ziyareti sırasında yaptığı anlaşmalar arasında Filipinlerin petrol ve doğalgaz ithalatına olan bağımlılı̆̆ını azaltmaya yardımcı olacak enerji projeleri de vardı. (Belt and Road News, 2019) Böylelikle, ilk üç ziyaretten farklı olarak ekonomik işbirliğinin ileri bir düzeye taşındığını ve daha fazla projenin konuşulduğunu gözlemlemek mümkündür. 2018'de Çin'in Filipinlere gerçekleştirdiği yatırımlar 930 milyon dolara ulaşmış ve Çin Filipinler'in en büyük yabancı yatırımcısı haline gelmiştir. (Hong,2019)

28 Ağustos- 1 Eylül 2019 tarihlerinde gerçekleşen beşinci ziyaret Güney Çin Denizi sorununun somut çözümü bağlamında doğrudan önem taşımaktaydı. (Cook, 2019) Çin lideri Şi Cinping Filipinler'in Güney Çin Denizi'ndeki Davranış Kuralları (The Code of Conduct in the South China Sea-COC) girişiminin benimsemesinin altını çizmiş ve bu girişime katılımı uzun vadeli bölgesel istikrar açısından öneminden bahsetmiştir. (Hong, 2019) 2018 y1lında ileri sürülen COC girişimi Güney Çin Denizi sorunu çerçevesinde Çin ve ASEAN ülkeleri arasında bir anlaşma yapılmasını öngörmekteydi.(Hong, 2019) Şi Cinping Çin ve Filipinlerin "Güney Çin Denizi sorunu bağlamında etkin işbirliğini” desteklediklerini ifade etmiştir. (Hong,2019) Çin liderine göre "taraflar anlaşmazlıkları bir kenara bırakmalı, dış müdahaleyi ortadan kaldırmalı ve pragmatik içerikli işbirliğine odaklanmalıdır.”(Hong,2019) Ziyaret kapsamında Çin Başbakanı Li Keqiang ile görüşen Duterte "Filipinlerin Güney Çin Denizi sorunu çerçevesinde Çin'le asla bir çatışmaya girmeyeceğini, Batılı ülkelerin COC müzakerelerine katılım göstermediklerini ve dolayısıyla bölge ülkelerinin uzlaşı konusundaki çabalarının engellenmemesi gerektiğini” vurgulamıştır.(Hong,2019)

Filipinler'in geleneksel olarak iyi ilişkilere sahip olmadığı ülkelerle işbirliği mekanizmasını kurması ve geliştirmesi Duterte yönetiminin pragmatik davranış çizgisinin bir yansımasıdır. Duterte Filipinler'in dış politika davranışlarını çeşitlendiren ve karşılıklı fayda sağlayan ortaklıkları önceleyen bir siyasal tavır sergilemektedir. ABD ile var olan geleneksel müttefikliği ve bağımlılığı azaltan stratejik hedef doğrultusunda ilişkilerin çeşitlendirilmesi öncelikli dış politika vizyonudur. Trump yönetimiyle karşılıklı anlayışa dayalı bir ilişki biçimi geliştirmeye çalışan Duterte yönetimi Çin ile ilişkilerde ise Güney Çin Denizi sorununun neden olduğu jeopolitik çatışma ihtimalini dışlayan siyasal söylem üretmektedir. Çin ile ilişkilerin doğası yeni uluslararası ilişkiler dinamiklerine uygun ortak ekonomik projeler aracılığıyla gelişim göstermektedir. Çin'in Tek Kuşak Tek Yol girişimine olumlu bir perspektiften yaklaşan Duterte bölgesel kalkınmanın firsatlarından maksimum faydalanmaya çalışmaktadır. Trump yönetiminin Asya-Pasifik stratejisinin kilit bir parçası olan Filipinlerin, ABD ve Çin arasında var olan bölgesel jeopolitik mücadeleyi denge politikaları çerçevesinde kendi lehine kullanma çabasında olduğunu gözlemlemek mümkündür. Duterte yönetimi sadece ABD ve Çin arasında değil, Rusya, Hindistan ve Japonya gibi aktörlerle ilişkilerinde de söz konusu denge unsurunu önceleyen bir dış politika davranış biçimine sahiptir.

\subsection{Rusya ile İlişkiler}

20 Kasım 2016 tarihinde Peru'nun başkenti Lima'da düzenlenen Asya Pasifik Ekonomik İşbirliği (APEC) Zirvesi sırasında Duterte'nin Rusya Devlet Başkanı Vladimir Putin ile ilk yüz yüze görüşmesi gerçeklemiştir. Görüşmede Duterte, "Putin'in liderlik özelliklerini övmüş ve onu 'idolü’ olarak gördüğünü belirtmiştir.” (Svedentsov, 2018:64) Duterte'nin Putin'e yönelik övgüsü sadece şahsi bir durum değildi, daha ötesinde Rusya ile yakın işbirliği kurma çabasıydı. Putin bu görüşmede Duterte'yi Moskova'ya resmi bir ziyaret yapmaya davet etmiştir. (Svedentsov,2018:64) Aralık 2016'da Rus televizyonuna verdiği mülakatta Duterte ülkesinin “1951'de ABD ile yaptığ1 Karşı1ıklı Savunma Antlaşması'nın (Mutual Defence Treaty) mevcudiyeti nedeniyle Rusya ve aynı zamanda Çin ile askeri ittifaklar için hazır olmadıklarını" vurgulamıştır.(Corrales,2016) Fakat yeni 
müttefiklerle (Rusya ve Çin) işbirliğine açık olduğunu yinelemiştir. (Corrales,2016) Rusya perspektifinden bu söylem "ABD'nin Filipinler'in esas müttefiki ve ortağı olarak kaldığının" tezahürüydü.(Panarina, 2017:160)

2016'da Rusya'nın Filipinler Büyükelçisi Khovayev “Rus hükümetinin Filipinler'e askeri bir ittifak değil, stratejik ortaklık" sunduğunu açıklamıştır. (Svedentsov, 2018:64) Aynı zamanda "Rus hükümeti terörle mücadele operasyonları ve isyancı eylemlere karşı mücadele kapsamında gerekli olan Rus yapımı silahların satın alınması konusunda Filipinler'e yardım etmeye hazır olduğunu" ifade etmiştir. (Svedentsov, 2018:64)

2017 yılının Mart ayında Duterte Rus donanması gemilerinin Filipin limanlarına serbestçe girişine izin vermiştir. Filipin lideri Nisan'da ise Manila limanındaki Varyag Rus füze kruvazorünü ziyaret etmiştir.(Svedentsov, 2018:65) 23 Mayıs 2017 tarihinde ise Duterte Moskova'ya resmi ziyarette bulunmuştur. Duterte, Putin ile görüşmesinde 'Filipinler'in DAEŞ'le mücadele kapsamında modern silahlara gereksinim duyduğunu ve bu bağlamda Rusya'dan yardım ve destek beklediklerini” ifade etmişsir.(Kremlin, 2017) Ziyaret sırasında Filipinler ve Rusya arasında savunma işbirliği anlaşması imzalanmıştır. Duterte'nin Moskova ziyareti DAEŞ menşeli aşırılıkçı grupların Filipinler'in güneyindeki Mindanao adasında bulunan Maravi kentini ele geçirmesiyle kesintiye uğramıștır.(Svedentsov, 2018:65) Daha Moskova'dayken Duterte Mindanao adasında altmış günlük sıkıyönetim ilan etmiştir. (Basisini,2017) Mindanao sorunu DAEŞ'in Filipinler'in güneyinde otonom halifelik ilanı etme çabaları çerçevesinde ülkenin temel güvenlik kaygılarından birini oluşturmaktadır. Seçim kampanyası sürecinde kendisi de Mindanao doğumlu olan Duterte, 1970'den itibaren devam eden sorunun müzakereler yoluyla çözülebileceğini düşünmekteydi. Fakat seçildikten sonra müzakere sürecine zarar veren bölgedeki uyuşturucu kaçakçılarına ve aşırılıkçı gruplara karşı savaş açmıştır. (Basisini,2017)

Ekim 2017'de ki ülkenin Savunma Bakanlarının bir araya geldiği ASEAN ve diyalog ortakları toplantısında askeri-teknik işbirliği konusunda bir anlaşma daha yapılmıştır.(Svedentsov,2018:65) Duterte'nin Rusya ile yakınlaşma stratejisinin öncelikli alanı Rus silahlarının satın alınmasıyla ilgili olmuştur. Bu çerçevede Filipinler lideri defalarca savunma sektöründe Rusya ile işbirliği yapmaya hazır olduğunu deklare etmiştir.(Svedentsov,2018:65) Daha 2015 yılında onaylanan ve Filipinler silahlı kuvvetlerinin modernizasyonunu öngören plan kapsamında ayrılan 998 milyar peso (22,11 milyar dolar) değerindeki bütçe söz konusu savunma ihtiyaçlarının karşılanmasını mümkün kılmaktadır. (Svedentsov,2018:65) Birçok çözüme kavuşturulmamış bölgesel çatışmanın mevcudiyeti ve aynı zamanda ABD ve Çin'in bölgeye artan ilgisine karşı önemli silah ihracatçısı olan Rusya, Filipinler açısından alternatif bir denge ve güç unsuru olarak görülmektedir. (Svedentsov,2018:65)

3 Ekim 2019'da Duterte Rusya'ya ikinci resmi ziyarette bulunmuştur. Söz konusu ziyaretin Filipinler ve ABD silahlı kuvvetlerinin ortak askeri tatbikatından bir hafta önce gerçekleşmesi dikkat çekmekteydi. (Pitlo,2019)

Duterte bu ziyaretin önemine dikkat çekmekte ve "Filipinler'i ve Rusya'yı etkileyen bölgesel ve küresel gelişmelerin müzakere edileceğini ve iki ülkenin ulusal çıkarlarını ilgilendiren birlikte çalışabileceğimiz konuların ele alınacağını" ifade etmekteydi. (Valente,2019) Duterte ve Putin uluslararası tartışma platformu olan Valday forumu kapsamında Soçi'de bir görüşme gerçekleştirmişlerdir. Duterte görüşmede "Filipinler ve Rusya arasındaki ilişkilerin son iki yıl içerisindeki gelişiminden duyduğu memnuniyeti” dile getirmiştir.(Kremlin,2019)

Valday forumunda 'Doğu'dan Dünya Düzenine Bakış" temalı bir konuşma gerçekleştiren Filipin lideri "savaş sonrası liberal düzenin meydana getirdiği iki temel zorluktan" bahsetti. Duterte'ye göre bu zorluklar "Pax American'nın istisnaların, çifte standartların ve jeopolitik değişimlerinin karışımından ibaret oluşunu ve bazı ülkelerin kendilerinin inşa ettiği küresel kurallar/normlar bağlı kalmayı reddetmelerini" ihtiva etmekteydi.(Pitlo,2019) Bu konuşma 
Duterte'nin retorik düzeyinde Batı karşıtı bir tutuma sahip bir lider olduğunu göstermemektedir. Filipin liderinin yapmak istediği ve arzuladığ 1 şey esasında küresel değişim döneminde bağımsız bir dış politika çerçevesinde ülkesini yönetmektir.(Pitlo,2019)

Duterte, oldukça güçlü komşusu Çin ile geleneksel müttefiki ABD arasında güçler dengesi inşa etmenin zorluklarını yaşamaktadır. Bu bakımdan Filipin lideri ülkesinin iç dinamiklerine ve dış politika konfigürasyonuna doğrudan etki edebilecek $A B D$ ve Çin'in bölgesel hegemonik arzularını azaltmak açısından Rusya'yı alternatif bir güç merkezi olarak değerlendirmektedir. Rusya ile ilişkilerde temel öncelik silah ithalatı yönünde gelişim göstermektedir. Filipinler'in güneyinde var olan aşırılıkçı gruplarla mücadele kapsamında söz konusu silah ithalatı elzem gözükmektedir. Rusya da silah ihracını çeşitlendirme ve yeni pazarlar elde etme bağlamında Duterte'yi önemli bir ortak olarak görmektedir. Rusya aynı zamanda çok kutuplu uluslararası ilişkiler perspektifinden Duterte'nin dünya düzenine dair taktiksel söylemlerini önemsemektedir.

\section{Sonuç}

Modern uluslararası ilişkilerde birçok ülke denge politikalarını temel stratejik öncelik olarak belirlemektedir. Bu çerçevede Asya -Pasifik bölgesinin önemli bir aktörü olan Filipinler ülkesi de istisna teşkil etmemektedir. 2016 yılında Filipin Cumhurbaşkanı seçilen Rodrigo Duterte söz konusu denge politikalarını uygulamaya çalışmaktadır. Filipinler lideri geleneksel müttefiki ABD ile Çin arasında güncel uluslararası sistemin çetin koşullarında çok boyutlu bir denge stratejisi izlemektedir. Duterte Çin'in ekonomik gücünü ülkesi lehine yapıcı bir perspektif sunduğu varsayımıyla hareket etmektedir. Diğer taraftan, geleneksel müttefiki ABD'ye tam anlamıyla yüz çevirmemektedir. Özellikle Trump'la karşılıklı çıkarlara dayalı bir politik işbirliği inşa etme istikametinde adımlar atmaktadır.

Filipinler' in Çin ile son yıllarda geliştirdiği ilişkilerin taktiksel boyutu orta vadede stratejik bir çerçeve kazanma potansiyeline sahiptir. Söz konusu stratejik çerçeve ABD'nin Asya-Pasifik politikaları açısından meydan okuyucu bir nitelik arz etmektedir. Bu nedenle Trump yönetimi Filipinler üzerinde kurduğu tarihsel üstünlüğünü ve kazançlarını yitirmeme arzusundadır. Filipinlerde bulunan ABD askeri üsleri Trump'ın Çin'i çevreleme stratejisi perspektifinden oldukça önem teşkil etmektedir. Trump yönetimi açısından bölgenin jeopolitik hattının kilit ülkesi konumunda olan Filipinler'in ABD etki alanından çıkması büyük bir stratejik kayıptır. Duterte ise $\mathrm{ABD}$ ve Çin arasında gelişen jeopolitik rekabetten azami ölçüde faydalanmak isteğindedir. İki büyük gücü askeri anlamda dengeleme bağlamında ise Rusya ile iyi ilişkiler inşa etmeyi de dış politikasının öncelikleri arasına almaktadır. Filipinler'in güneyinde devam eden aşırılıkçı gruplarla mücadele kapsamında Rusya ile askeri işbirliği ön plana çıkmaktadır.

Duterte ABD'nin Filipinler üzerinde kurduğu tek taraflı hegemonyanın şiddetinin azaltmayı ve Çin ile ilişkileri çeşitlendirmeyi temel stratejik öncelik olarak belirlemiştir. Bu açıdan Çin ile var olan Güney Çin Denizi sorununda geri adım atmaktan bile çekinmemiş ve ekonomik işbirliğine dayalı ilişkiler bütünü inşa etmeyi öncelemiştir. Duterte'nin anti ABD politikalarını benimseyen bir siyasal çizgiye sahip olduğu söylenemez. Filipin liderinin çok kutuplu sistemde ulusal çıkar kavramı perspektifiyle hareket ettiğini ve denge politikası stratejisini izlediğini söylemek mümkündür.

\section{Kaynakça}

Arugay, A. (2018). From Arbitration to Diplomacy: Duterte's Performative Populist Approach to the South China Sea Issue, Observatoire Asie du Sud -Est, 1-7.

Bader, J. Lieberthal, K. McDevitt, M. (2014). Keeping the South China Sea in Perspective, The Foreign Policy Brief Brookings, 1-11. 
Basisini,A. (2017). Pochemu Glava Filippin Duterte Prerval Svoi Perviy Vizit v Moskvu, RBC, https://www.rbc.ru/politics/24/05/2017/592559d39a7947d9fd9f92bf (14.03.2020).

Blanchard, B. (2016). Duterte Aligns Philippines with China, says U.S. has lost, Reuters, https://www.reuters.com/article/us-china-philippines/duterte-aligns-philippines-with-chinasays-u-s-has-lost-idUSKCN12K0AS (12.03.2020).

Castro, R, C. (2016). The Duterte Administration's Foreign Policy: Unravelling the Aquino Administrations's Balancing Agenda on an Emergent China, Journal of Current Southeast Asian Affairs, 35(3), 139-159.

Castro, R, C. (2019). From Appeasement to Soft Balancing: The Duterte Administration's Shifting Policy on the South China Sea Imbroglio, Research Division Asia,BCAS, 4, 1-11.

Choi, J. (2017). The South China Sea Dispute: Simulating the Next Global Conflict, Pksoi Trends Globalcase Study Series, 1-6.

Cook, M. (2019). The Duterte Administration's China Tensions, Perspective,Singapur, Yusof Ishak Institute, 69, 1-8.

Corrales, N. (2016). Duterte: PH not ready for Military Alliances with Russia, China, Inquirer Paper, https://globalnation.inquirer.net/150287/duterte-ph-not-ready-military-alliancesrussia-china (09.03.2020).

Davis, J. (2017). Trump Lauds 'Great Relationship' With Duterte in Manila, The New York Times, https://www.nytimes.com/2017/11/13/world/asia/trump-duterte-philippines.html\%20Davis (10.03.2020).

Duterte Secures \$12 Billion Deals from China. Belt and Road News, 27 Nisan 2019, https://www.beltandroad.news/2019/04/27/duterte-secures-12-billion-deals-from-china/ (14.03.2020).

EU-Asia Centre, (2013). South China Sea: Background Note, 1-4.

Fook, L. (2019). China-Philippino Relations: Duterte's China Visit and Prospects for Oil and Gas Exploration, Perspective,Singapur, Yusof Ishak Institute, 80, 1-9.

Forsby, A, B. (2016). The South China Sea: A Breeding Ground for Geopolitical Rivalry, Danish Institute for International Relations, 5-33.

Gavilan, J. (2016). The Many Firsts of President -Elect Duterte, Rappler, Philippines -Indonesia, https://www.rappler.com/newsbreak/iq/132862-rodrigo-duterte-president-firsts (10.03.2020).

Heydarian, R, J. (2018). An Unlikely Bromance: Trump, Duterte and the Future of Philippine-U.S. Alliance, Asia Trends, 1-6.

Hong, C. (2019). Duterte's China visit Boosts Relations, China Daily, 3 Eylül 2019, http://www.chinadaily.com.cn/global/2019-09/03/content_37507260.htm (10.03.2020)

Ibarra, E, J. (2017). The Philippines 'Pivot' to China: A Review of Perspectives, Center for International Relations \&Strategic Studies, 4(9), 1-2.

Kapustin, N. (2017). Territorialniy Konflikt v Yujno-Kitayskom More: Pricini i Varianti Razvitiya, Theories and Problems of Political Studies, 6 (1), 206-216.

Keyvan, Ö, Z. (2017). Güney Çin Denizi'nde Tahkim: Çin-Filipinler Rekabeti, ANKASAM Bölgesel Araştırmalar Dergisi, 1(3), 251-267. 
Kozlov, D. (2018). Territorialniy Spori v Yujno-Kitayskom More: İzmeneniya v Treugolnike Otnosheniya Kitay-SSA-Filippini, Moscow University for the Humanities, 1-10.

Kreuzer, P. (2018). Dealing with China in the South China Sea: Duterte Changing Course, PRIF Report, 3, Peace Research Institute Frankfurt, Hessische Stiftung Friedens und Konfliktforschung, 1-33.

Kurlantzick, J. (2020). Is Duterte Trying to End the U.S. -Philippines Alliance?, World Politics Review, https://www.worldpoliticsreview.com/articles/28549/us-philippines-relations-takea-hit-as-duterte-axes-a-key-military-pact (14.03.2020).

Manukov, S. (2016). Pekin Zamanivaet Malinu, Expert Online, https://expert.ru/2016/10/21/filippinyi/ (12.03.2020).

National Government Portal. (2019). Build, Build, Build Program, Fact s and Figures, Congressional Policy and Budget Research Department House of Representatives, 7, 1-2.

Novoseltsev, S. (2018). Konflikt v Yujno-Kitayskom More v XXI veke: Evolutsiya Pozitsyii Uchastnikov, Sravnitelnaya Politika, 9(3), 88-100.

Panarina, D. (2016). Filippini v Yujno-Kitayskom More: Pozitsiya Strani Posle Resheniya Gaagskogo Suda, Yugo-Vostochnaya Azia: Aktualnie Problemi Razvitiya, 32, 91-100.

Pekcan, C. (2017). Uluslararası Hukuk Çerçevesinde Güney Çin Denizi Krizinin Değerlendirilmesi, ANKASAM Uluslararası Kriz ve Siyaset Araştırmaları Dergisi, 1(3), 54-80.

Pitlo, B, L. (2019). What Does Duterte's Valdai Speech Mean for Philippine Foreign Policy, The Diplomat, https://thediplomat.com/2019/10/what-does-dutertes-valdai-speech-mean-forphilippine-foreign-policy/ (12.03.2020).

Rustandi, C,A. (2016). The South China Sea Dispute: Opportunities for ASEAN to Enhance its Policies in Order to Achieve Resolution, Australian Defence College, Centre for Defence and Strategic Studies, 1-23.

Sevilla, H. (2018). The Philippines Foreign Policy Direction: An Assessment of the First Year of President Duterte, Journal of South Asian Studies, 06(2), 165-173.

Shoji, T. (2017). Southeast Asia: Duterte Takes Office, South China Sea in Flux, http://www.nids.mod.go.jp/english/publication/east-asian/pdf/2017/eastasian e2017 05.pdf $(10.03 .2020)$ 